ECCOMAS Proceedia
COMPDYN 2021

$8^{\text {th }}$ ECCOMAS Thematic Conference on Computational Methods in Structural Dynamics and Earthquake Engineering M. Papadrakakis, M. Fragiadakis (eds.) Streamed from Athens, Greece, 28 - 30 June 2021

\title{
ESTIMATION OF DUCTILITY IN ASYMMETRIC-PLAN STRUCTURES
}

\author{
Kaan Kaatsız $^{1}$ and Halûk Sucuoğlu ${ }^{2}$ \\ ${ }^{1}$ Department of Civil Engineering, Ahi Evran University \\ 40100 Kırşehir, Turkey \\ e-mail: kaan.kaatsiz@ahievran.edu.tr \\ ${ }^{2}$ Department of Civil Engineering, Middle East Technical University \\ 06800 Ankara, Turkey \\ e-mail: sucuoglu@metu.edu.tr
}

\begin{abstract}
Ductility demands observed in asymmetric plan structures due to earthquake excitations are investigated in this study. Torsional Ductility Spectra are utilized to estimate the maximum ductility response of such systems. Dynamic response of these systems are dominated by the lower vibration modes and observed seismic behavior is in conformance with the capacity design principles. In order to utilize the Torsional Ductility Spectra, five parameters of the asymmetric plan systems, namely, first mode period, uncoupled frequency ratio, stiffness eccentricity, stiff-to-flexible edge strength ratio and ductility reduction factor are estimated through a novel procedure. Simple formulations for representing the dynamic properties of shear frame systems in terms of described structural parameters are developed. Parametric equivalents of shear frame structures are obtained. Estimated ductilities form the developed charts are compared with those obtained from dynamic response analyses of shear frame asymmetric-plan systems.
\end{abstract}

The observed results indicate that developed spectra are able to estimate the ductility demands at both stiff and flexible side frames of actual asymmetric-plan systems with reasonable accuracy. Based on the conclusions, Torsional Ductility Spectra charts are considered practical tools for estimating the ductility demands of asymmetric plan structures.

Keywords: Asymmetric-plan Structures, Torsional Coupling, Torsional Ductility, Ductility Distribution, Performance Assessment 


\section{INTRODUCTION}

Modern seismic design codes employ response reduction factors in design of structural members using linear elastic analysis $[1,2]$. The capacity design methodology employing the response reduction factors may result in poor estimation of seismic performance in the case of irregular structures such as asymmetric-plan systems where torsionally coupled behaviour is observed. The resulting poor seismic performance, in turn, yields uneven ductility distribution among plan of asymmetric structures. Hence, varying degrees of inelastic behaviour is observed.

The discussed problem is a well-known issue and in the past it has been addressed in many studies. Comprehensive reviews of these studies has been made by various authors previously $[3,4,5,6]$. Early research regarding the subject was performed using simple single-story models. Later more advanced studies based in multi-story asymmetric systems have also emerged. In one of the early studies, the reducing effect of torsional coupling with increasing inelastic deformations was observed [7]. An effective eccentricity and associated design torque was introduced to estimate the inelastic deformations of torsionally-coupled systems [8]. Peak ductility demands at the edges of asymmetric systems are determined to be not larger than those of symmetric systems $[9,10]$. Moreover, it was proposed that, the inelastic displacements of asymmetric systems can be reduced by modifying the strength distribution along plan by changing the location of center of strength $(\mathrm{CV})$. In separate other studies, strength eccentricity has been determined to be more effective than stiffness eccentricity to control inelastic deformations [11, $12,13]$. A displacement-based design approach has also been proposed as an alternative to strength-based approach to limit and make ductility distribution among structural members in asymmetric systems more uniform [14]. A balanced distribution of center of strength and center of stiffness was proposed in order to minimize the edge displacements of torsionally coupled systems [15]. Contribution of load resisting frames that are perpendicular to the direction of earthquake loading to the torsional response was also investigated [16, 17].

The overstrength that is inherent in members of the torsionally coupled systems which are designed with force-based approaches has also been studied. It has been noted that accidental eccentricity formulations in seismic codes does not usually compensate the inelastic deformation demands, rather they increase the overstrength $[18,19]$. The explicit inclusion of overstrength in the design of asymmetric systems was suggested in a study regarding the uneven distribution of overstrength in torsionally coupled multistory buildings [20]. Further studying the overstrength in asymmetric systems, uniform ductility spectra which has been proposed by the authors to estimate the optimum strength ratio of stiff and flexible sides of asymmetric systems for achieving balanced ductility demands [21].

The observations and suggestions regarding the torsional response of asymmetric systems vary dramatically among the vast research conducted in the past. Although this is the case for many of the deductions, it has been generally agreed by the researchers that the modification of strength eccentricity is closely related with controlling the inelastic torsional response. The work presented within this study is formulated upon this observation. The inelastic displacements of asymmetric systems are estimated with respect to strength distribution of these simple structures. Seismic response of shear frame systems is represented by simple models using basic dynamic properties.

\section{TORSIONAL DUCTILITY SPECTRA}

A simple tool to assess the ductility demands in simple asymmetric-plan multi degree of freedom systems is proposed. Basic vibration and strength parameters of a simple single story, two degree of freedom asymmetric shear frame are determined as the basic variables for a rigorous parametric study. A shear frame having a stiffness eccentricity ratio of $e$ is constructed. 
It is composed of a stiff side and flexible side structural member, both of which are connected a rigid slab. The system in question is designed under a typical design spectrum by employing the ductility reduction factor $R \mu$.

Another parameter that is taken into account is the uncoupled frequency ratio $\left(\Omega_{r}\right)$ of the parametric system. A variation for $\Omega_{r}$ is introduced so that the variation in seismic response of a torsionally stiff $\left(\Omega_{r}=1.25\right)$, torsionally equally stiff $\left(\Omega_{r}=1.0\right)$ and torsionally flexible $\left(\Omega_{r}=\right.$ $0.8)$ systems are investigated. The different parameters considered in this simple, single story shear frames are summarized in Table 1.

\begin{tabular}{lll}
\hline$e$ & $R \mu$ & $\Omega_{r}$ \\
\hline 0.1 & 3 & 1.25 \\
0.2 & 4 & 1.0 \\
0.3 & 5 & 0.8 \\
\hline
\end{tabular}

Table 1: System parameters used in single-story simple structures

The stiffnesses of flexible and stiff side members of the linear elastic system ( $k_{F}$ and $\left.k_{S}\right)$ are selected such that the target stiffness eccentricity value is satisfied for each parametric system (Equation 1).

$$
e=\frac{k_{F}-k_{S}}{2\left(k_{F}+k_{S}\right)}
$$

The uncoupled frequency ratio can also be computed from Equation 2. $L$ in Equation 2 is the distance between to structural members and $r$ is the radius of gyration of the system (Equation 3.)

$$
\begin{aligned}
& \Omega_{r}=\frac{L}{2 r} \\
& r=\sqrt{\frac{I_{C M}}{m}}
\end{aligned}
$$

The terms $m$ and $I_{C M}$ in Equation 3 are the mass and the mass moment inertia of the parametric systems, respectively. Throughout the parametric study, $L$ and $m$ are utilized as unity. Solution of Equation 3 for each $\Omega_{r}$ value yields the $L$ parameter which, in turn, used to compute mass moment of inertia and create the mass matrix of the system. In addition, Equation 1 is used to determine $k_{F}$ and $k_{S}$ for every parametric system having $e=0.1,0.2$, or 0.3 . Upon using the determined stiffness values and $L$, the stiffness matrix for each unique system can also be obtained. Consequently, the relationship between modal vibration frequency $\omega_{n}$, stiffnesses $k_{F}$ and $k_{S}$, and the inertial properties $m$ and $I_{C M}$ of the parametric system can be obtained from the solution of the eigenvalue problem in Equation 4:

$$
\operatorname{det}\left(\underline{k}-\omega_{n}^{2} \underline{m}\right)=0
$$

Hence, upon solution of Equation 4, the linear elastic properties of the systems can be obtained for a range of different translational periods $\left(T_{1}\right)$. They are designed under the design response spectrum for obtaining the stiff side and flexible side strength demands for selected ductility reduction factors of $R_{\mu}$. The schematic representation of the parametric systems and 
the distribution of displacements computed under response spectrum analysis is shown in Figure 1. It should be noted here that accidental eccentricity is not included in the design.

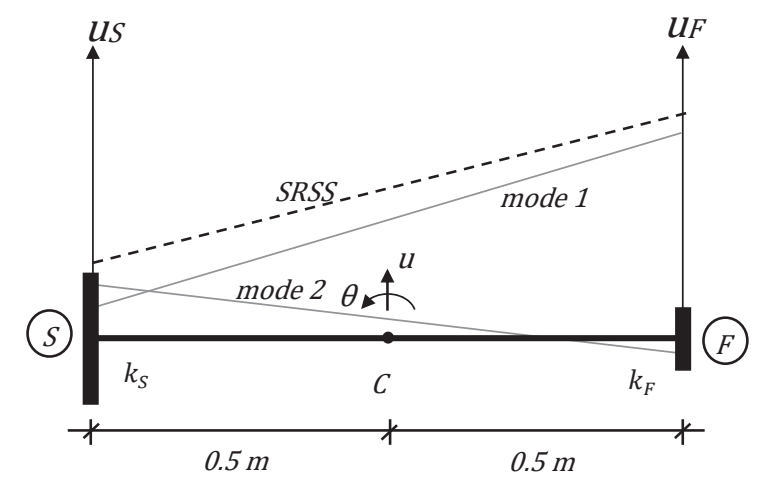

Figure 1: Schematic distribution of displacements for a 2DOF parametric system.

At this stage, another parameter variation is introduced to the parametric systems. The assigned flexible side strength $\left(F_{F}\right)$ is kept fixed at its nominal value (i.e. the strength demand); whereas overstrength is introduced to the stiff side members in an incremental manner (Figure 2). Hence, the parameter stiff to flexible edge strength ratio $(S F S R)$ is defined (Equation 5).

$$
S F S R=\frac{F_{S}}{F_{F}}
$$

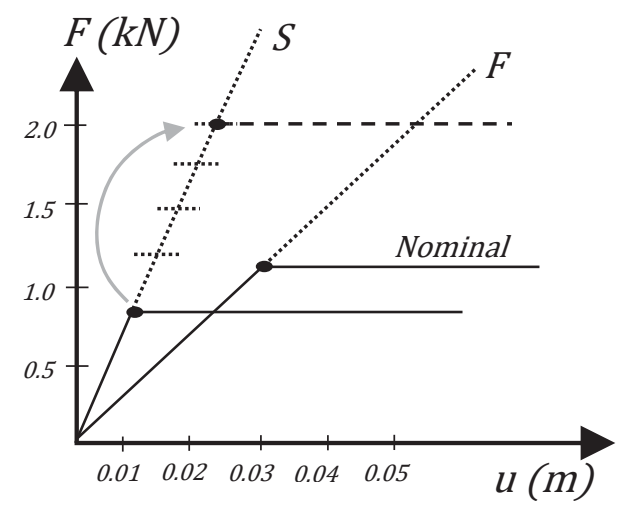

Figure 2: The flexible $\left(F_{F}\right)$ and stiff edge $\left(F_{S}\right)$ strengths of the parametric systems and variation of $F_{S}$.

By utilizing this procedure, a family of parametric, two degree of system parametric systems are obtained. Each system is identified by a unique set of parameters $\left(T_{1}, \Omega_{r}, e, R_{\mu}, S F S R\right)$. Nonlinear dynamic response of these systems are then computed under a set of 30 spectrum matched [22] ground motions selected from PEER NGA Database [23]. The unscaled ground motion list and their characteristics are given in Table 2. Generally, they are all recorded in soft soil, at near fault regions. Linear elastic target spectrum is constructed per ASCE 7-16 [1] based on an imaginary location in downtown San Francisco. The site class is assumed as C.

Nonlinear models of the parametric systems have been prepared in OpenSees Platform [24] and elastic-perfectly plastic hysteresis models are employed in numerical representations of load resisting members. 


\begin{tabular}{llcccc}
\hline $\begin{array}{l}\text { PEER NGA } \\
\text { Code }\end{array}$ & \multicolumn{1}{c}{$\begin{array}{c}\text { Earthquake } \\
\text { TMB205 }\end{array}$} & Parkfield - 1966 & $\begin{array}{c}\text { Joyner- } \\
\text { Boore Dist. } \\
(\mathrm{km})\end{array}$ & $\begin{array}{c}\text { NEHRP } \\
\text { Site Class }\end{array}$ & $\begin{array}{c}\text { PGA } \\
(\mathrm{g})\end{array}$ \\
\hline UC2090 & Loma Prieta - 1989 & 6.19 & 15.96 & $\mathrm{C}$ & 0.29 \\
WPI046 & Northridge-01 - 1994 & 6.93 & 12.15 & $\mathrm{C}$ & 0.34 \\
A-TAR000 & Whittier Narrows-01 - 1987 & 5.69 & 2.11 & $\mathrm{D}$ & 0.38 \\
ABBAR--L & Manjil, Iran - 1990 & 7.37 & 12.56 & $\mathrm{D}$ & 0.60 \\
AND250 & Morgan Hill - 1984 & 6.19 & 3.22 & $\mathrm{C}$ & 0.51 \\
B-PTS225 & Superstition Hills-02 - 1987 & 6.54 & 0.95 & $\mathrm{C}$ & 0.34 \\
C05085 & Parkfield - 1966 & 6.19 & 9.58 & $\mathrm{D}$ & 0.45 \\
CPE045 & Victoria, Mexico - 1980 & 6.33 & 13.80 & $\mathrm{C}$ & 0.38 \\
375-E & Duzce, Turkey - 1999 & 7.14 & 3.93 & $\mathrm{C}$ & 0.57 \\
DAY-LN & Tabas, Iran - 1978 & 7.35 & 20.63 & $\mathrm{C}$ & 0.35 \\
DZC270 & Kocaeli, Turkey - 1999 & 7.51 & 13.60 & $\mathrm{D}$ & 0.33 \\
G02090 & Loma Prieta - 1989 & 6.93 & 10.38 & $\mathrm{D}$ & 0.35 \\
G03090 & Loma Prieta - 1989 & 6.93 & 12.23 & $\mathrm{D}$ & 0.46 \\
H-E07230 & Imperial Valley-06-1979 & 6.53 & 0.56 & $\mathrm{D}$ & 0.42 \\
H-E08230 & Imperial Valley-06 - 1979 & 6.53 & 3.86 & $\mathrm{D}$ & 0.54 \\
HEC090 & Hector Mine - 1999 & 7.13 & 10.35 & $\mathrm{C}$ & 0.31 \\
KAK090 & Kobe, Japan - 1995 & 6.90 & 22.50 & $\mathrm{D}$ & 0.27 \\
LGP090 & Loma Prieta - 1989 & 6.93 & 18.46 & $\mathrm{C}$ & 0.78 \\
LOB000 & Loma Prieta - 1989 & 6.93 & 12.04 & $\mathrm{C}$ & 0.46 \\
MU2035 & Northridge-01 - 1994 & 6.69 & 12.39 & $\mathrm{C}$ & 0.51 \\
NWH360 & Northridge-01 - 1994 & 6.69 & 3.16 & $\mathrm{D}$ & 0.70 \\
OBR360 & Northridge-01 - 1994 & 6.69 & 35.43 & $\mathrm{D}$ & 0.47 \\
ORR360 & Northridge-01 - 1994 & 6.69 & 20.10 & $\mathrm{C}$ & 0.49 \\
PAR--T & Northridge-01 - 1994 & 6.69 & 5.54 & $\mathrm{D}$ & 0.51 \\
A-MAT353 & New Zealand-03 - 1987 & 5.80 & 26.85 & $\mathrm{C}$ & 0.05 \\
STG000 & Loma Prieta - 1989 & 6.93 & 7.58 & $\mathrm{C}$ & 0.38 \\
STM360 & Northridge-01 - 1994 & 6.69 & 17.28 & $\mathrm{D}$ & 0.59 \\
STN110 & Whittier Narrows-01 - 1987 & 5.99 & 20.35 & $\mathrm{D}$ & 0.12 \\
SYL090 & Whittier Narrows-01 - 1987 & 5.99 & 38.55 & $\mathrm{C}$ & 0.06 \\
\hline
\end{tabular}

Table 2: Strong ground motions used in the dynamic analyses.

Results obtained from nonlinear dynamic analysis of each parametric system having a distinct $T_{1}$ are compiled in a spectrum format to create the Torsional Ductility Spectra. The main response parameter in this spectra set is selected as the mean maximum ductility of the systems. Ductility is a normalized indication of the inelastic response; therefore, it provides an objective response comparison for all parametric systems. Torsional Ductility Spectra produced for $R_{\mu}=$ 3, 4, and 5 are presented in Figures 3, 4, and 5 respectively. The spectra compiled only for torsionally stiff and torsionally equally flexible systems are displayed in these figures in order to not to make the graphical view too complicated. 


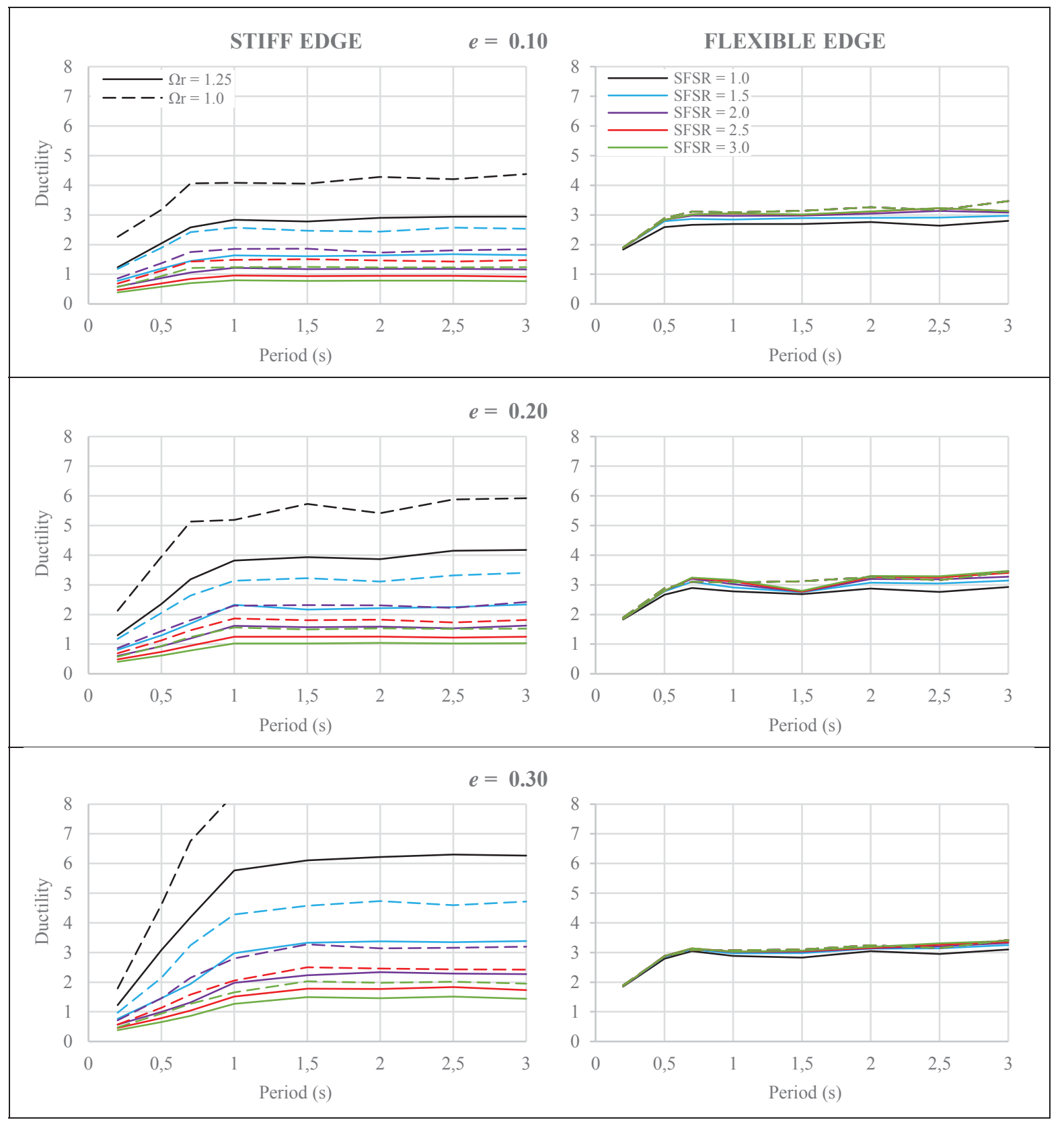

Figure 3: Torsional ductility spectra $(R \mu=3)$.

\subsection{Observations from Torsional Ductility Spectra}

As can be seen in Figures 3, 4 and 5 the ductility trends of stiff and flexible side members vary considerably. Flexible side ductilities are invariant of SFSR and almost equal to $R \mu$ in each chart. Stiff side ductilities, however, are quite sensitive to SFSR. It should be noted here that the variation in SFSR corresponds to the proportional variation of stiff side strength since the flexible side strength is held fixed at its nominal value among designs.

An important observation could be made from Figures 3, 4 and 5. The ductilities observed in flexible edge members are consistent with the ductility reduction factors employed in the design. Therefore, it could be concluded that energy is dissipated mainly through flexible side member. Stiff side member may also experience some inelastic response especially when SFSR 
is close to unity (stiff and flexible sides have similar strengths). Although in practice, this observation is not common. Due to relationship between strength and stiffness, the ratio of stiff side to flexible side strength (SFSR) is proportional to the ratio of stiff side to flexible side stiffness in most of the cases. This issue, in turn, is the cause of torsional behaviour and the cause of inherent overstrength located in stiff side members. Therefore, it can be deduced that the stiff side members in actual systems behave in a force-controlled manner with fairly small ductility demands. This is visualized in Figures 3, 4 and 5 especially when $S F S R>2$. It is also well known that ductile seismic detailing supplied to structural members further increase the overstrength for stiff side, hence making the behaviour more unfavorable.

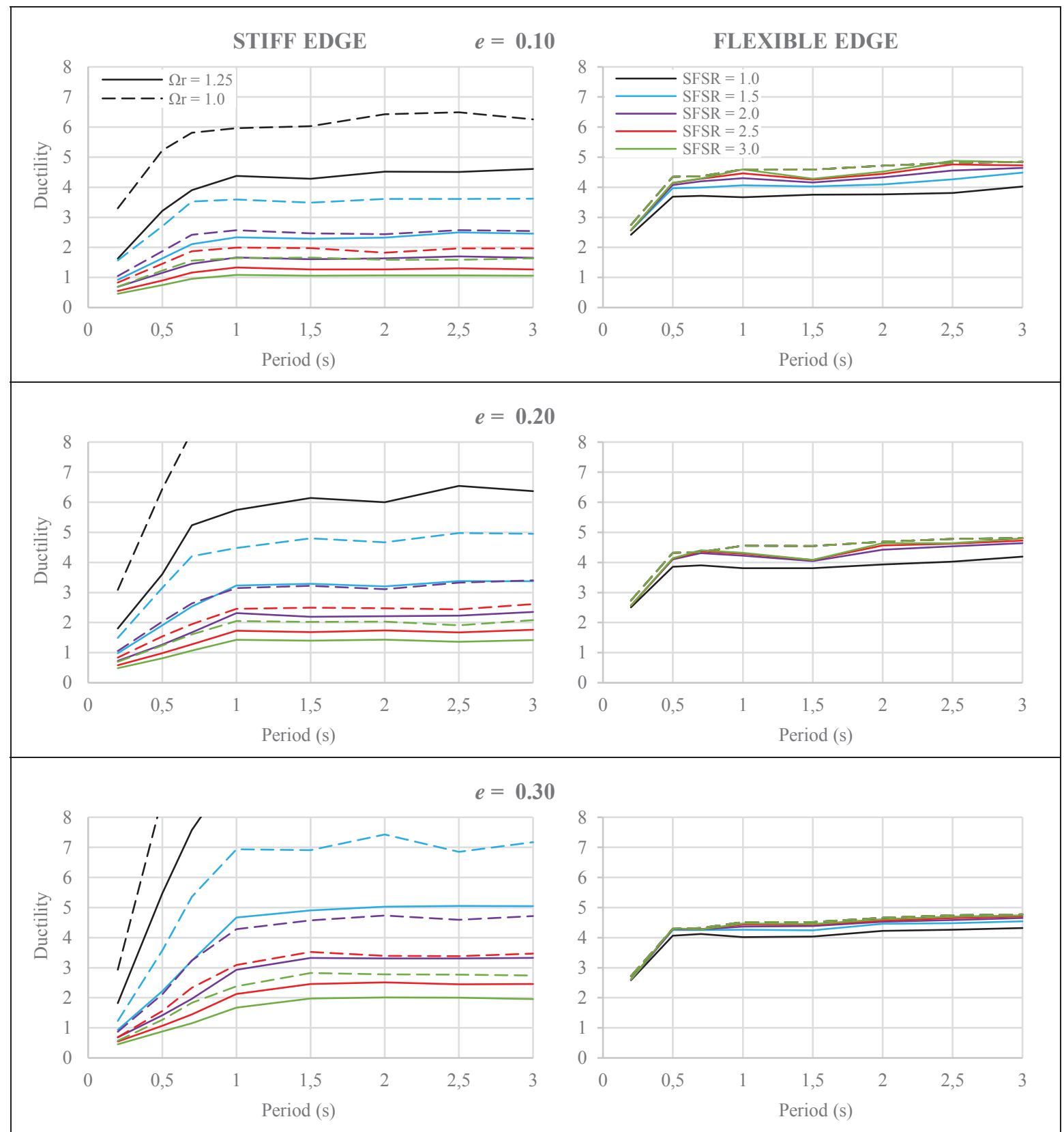

Figure 4: Torsional ductility spectra $(R \mu=4)$. 


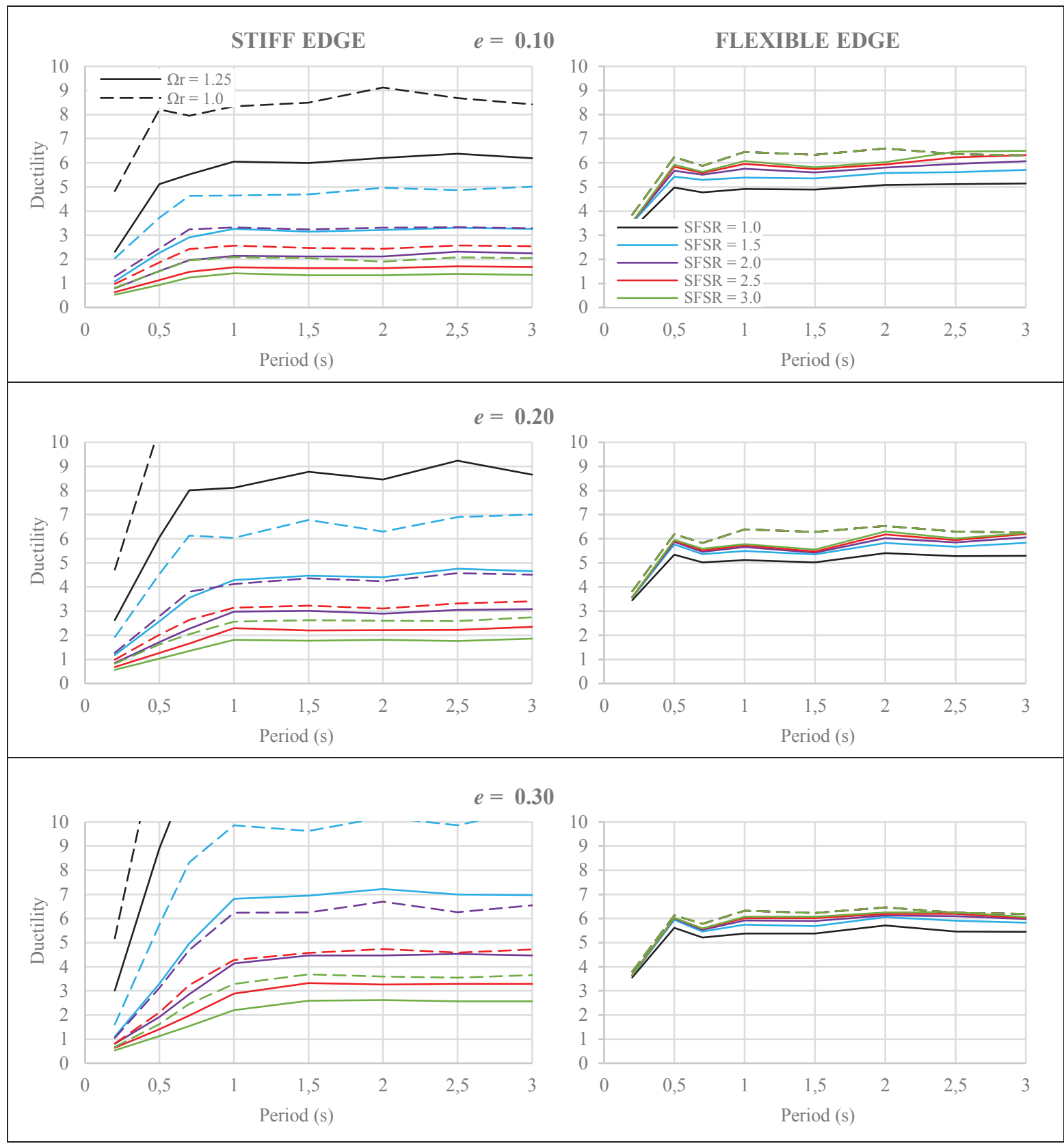

Figure 5: Torsional ductility spectra $(R \mu=5)$.

The effect of uncoupled frequency ratio is assessed comparatively for uncoupled rotationalto-translational frequency ratios of $1.25,1.0$ and 0.8 . The results are presented in a separate figure (Figure 6) for $R_{\mu}=4, S F S R=1.0,2.0,3.0$ and $e=0.1,0.2$ combinations. It can be seen from Figure 6 that stiff edge ductilities are quite sensitive to increasing values of torsional flexibility whereas flexible edge ductilities are not affected considerably. As a general trend, stiff side ductility demands exhibit an increasing trend with decreasing frequency ratio. Hence, it could be concluded that the torsionally flexible systems display more non-uniform ductility distribution. This observation is consistent with the fact that modern earthquake codes which discourage or penalizes the design of torsionally flexible systems. 


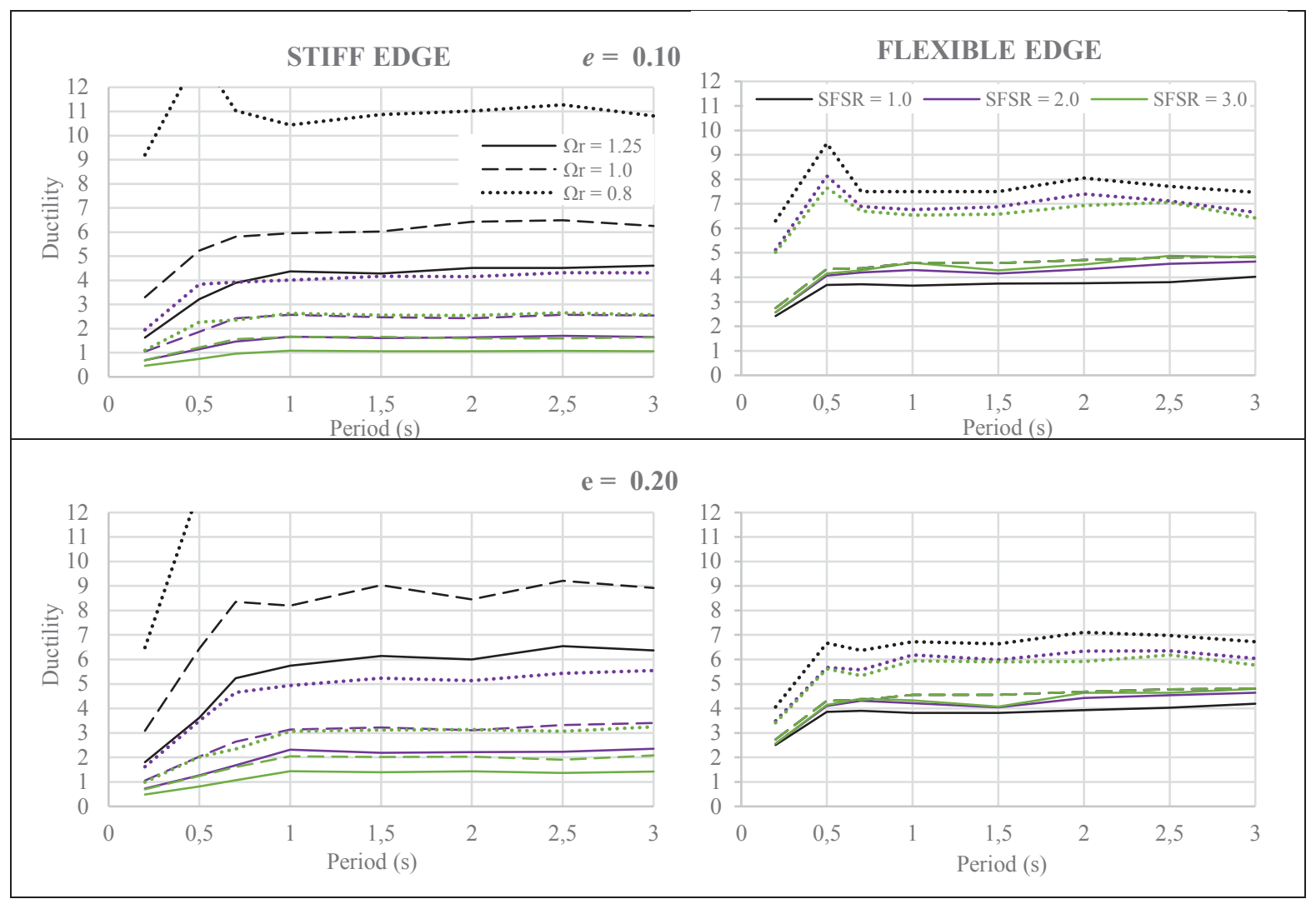

Figure 6: Sensitivity of the compiled spectra to uncoupled frequency ratio $(R \mu=4)$.

\section{ESTIMATION OF DUCTILTIES VIA TORSIONAL DUCTILITY SPECTRA}

The torsional ductility spectra presented herein is a tool for estimating the ductility distribution of a 2DOF, 2-member system. In order to utilize the spectra set in performance assessment, more realistic structural systems having varying number of load resisting frames must be "transformed" to the schematic 2DOF system. In this section, a single-story shear frame having four load resisting members is investigated.

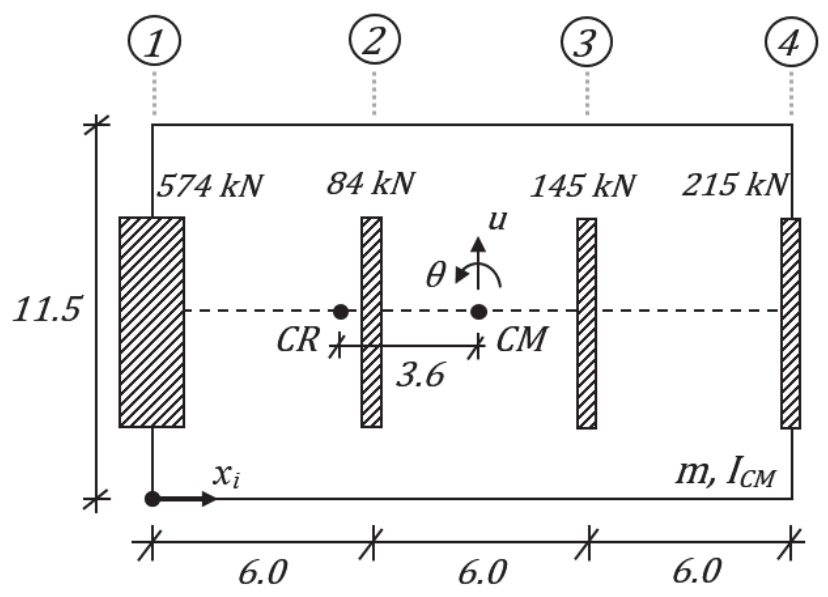

Figure 7: 4-member shear frame system. 
The plan view of the 4-member shear frame is shown in Figure 7. The dimensions and related geometric properties of the system are selected such that they represent an actual structure. The rigid slab dimensions are $18 \mathrm{~m}$ by 11.5 meters, with a mass of 340 tons. Member 1 is 3.7 times more stiff than members 2,3 , and 4 . Consequently, the system has $e=0.2$ static eccentricity towards member 1 . The lateral stiffness values to the load resisting members are given such that modal vibration periods of $T_{1}=0.7 \mathrm{~s}, T_{2}=0.4 \mathrm{~s}$ and uncoupled frequency ratio $\Omega_{r}=1.25$. The system is designed under the same ASCE 7-16 [1] design spectrum used in parametric study with $R \equiv R_{\mu}=4$. Since $R \equiv R_{\mu}$, no overstrength is considered for all members. The resulting strengths determined from design and corresponding force-deformation relationships of 4 members are given in Figure 8.

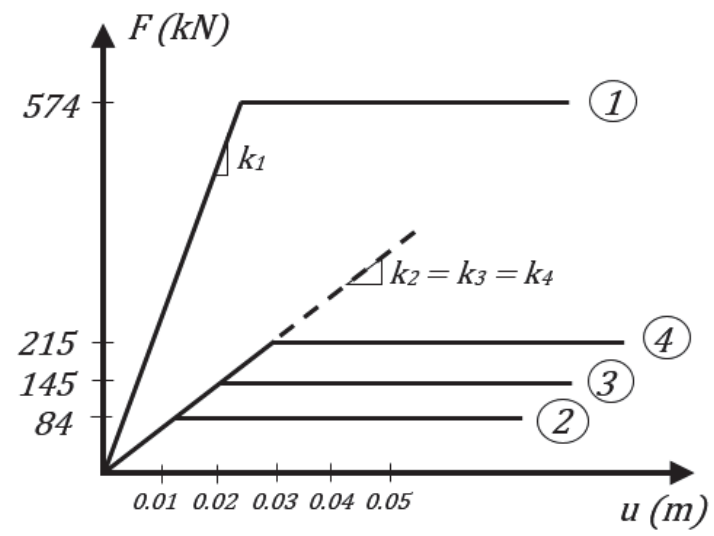

Figure 8: Force-deformation relationships of load resisting members.

All values related with the parametric systems $\left[T_{1}, \Omega_{r}, e, R_{\mu}\right]$ except $S F S R$ are obtained. Since SFSR defined within this study depends on single values of $F_{S}$ and $F_{F}$, strength capacities of four members should be transformed. This could easily be achieved by satisfying the two equations of force equilibrium in Equation 6. $x_{i}$ in Equation 6 is the location of frame $i$ in the 4-Member system.

$$
F_{F}=\frac{\sum_{i}\left(F_{i} \cdot x_{i}\right)}{L} ; \quad F_{S}=\left(\sum_{i} F_{i}\right)-F_{F}
$$

Using frame strengths and their respective locations in Equation $6, F_{F}=340 \mathrm{kN}$ and $F_{S}=$ $678 \mathrm{kN}$. Therefore, SFSR is calculated as 2.0. Since all parameters of the structural system is now known, corresponding Torsional Ductility Spectra given in Figure 4 with associated parameters of $T_{1}=0.7 \mathrm{~s}, \Omega_{r}=1.25, e=0.2, R_{\mu}=4$ and $S F S R=2.0$ can be used to obtain the estimated ductilities. From the related chart, stiff edge ductility is read as $\mu_{S}=1.7$, whereas flexible edge ductility is read as $\mu_{F}=4.3$.

In order to verify the accuracy of this estimation, actual nonlinear performance of the shear frame should be determined. Nonlinear response history analyses (NRHA) are performed on the shear frame system using the ground motion set given in Table 2. Load resisting members are defined with elastic-perfectly plastic hysteretic relationships in OpenSees Platform [24] using the yield force and deformation parameters given in Figure 8. Mean maximum inelastic member displacements are obtained from the dynamic analyses under the ground motion set and corresponding member ductility ratios are computed. Mean member displacements, member yield deformations shown in Figure 8 and corresponding member ductility ratios are given in Equation 7. 


$$
\begin{aligned}
& \text { Member 1: } \\
& \text { Member 2: } \\
& \text { Member 3: } \\
& \text { Member 4: }
\end{aligned} \quad \underline{u}_{N R H A}=\left\{\begin{array}{l}
0.039 \\
0.055 \\
0.096 \\
0.145
\end{array}\right\} \quad \underline{u}_{y}=\left\{\begin{array}{l}
0.0241 \\
0.0129 \\
0.0224 \\
0.0331
\end{array}\right\} \quad \mu_{N R H A}=\left\{\begin{array}{l}
1.6 \\
4.3 \\
4.3 \\
4.4
\end{array}\right\}
$$

In order to compare the computed ductility ratios with estimations from the Torsional Ductility Spectra, members located at stiff and flexible sides of the shear frame system should be determined. This can be done by inspecting Figure 7 in a fairly straightforward manner. Member 1 is at the stiff side of the shear frame structure with respect to center of rigidity $(C R)$; whereas members 2-4 are at the flexible side. Hence, comparison of ductilities estimated from Torsional Ductility Spectra and dynamic analyses can be made accordingly.

Upon comparing the estimation with the dynamic response, a close match can be seen. Mean member ductility ratios obtained from NRHA are seemingly close to the ductility estimations for both sides given by the associated spectrum. It should be noted here that ductility ratios of flexible side members are determined to be close to the imposed value of $R_{\mu}=4$. On the other hand, mean ductility ratio of the stiff side member is considerably smaller than other members as well as imposed $R_{\mu}$. In practice, significant overstrength is expected to be present in the stiff side member due to factors such as seismic detailing and relationship between strength and stiffness. Therefore, the ductility imbalance shown here is expected to further increase in the case of a more realistic case study structure.

\section{SUMMARY AND CONCLUSIONS}

Torsional Ductility Spectra as a tool for estimating ductilities and their distribution among asymmetric-plan systems are presented in this study. Basic 2DOF 2-member parametric systems are utilized and through a parametric study considering stiffness eccentricity, frequency ratio, ductility reduction factor, fundamental period and strength ratio, system ductilities are compiled in a spectrum format. Last parameter in question, stiff to flexible strength ratio (SFSR) is introduced to the systems such that flexible side members are kept at their nominal strengths whereas overstrength is introduced in stiff side members. By doing so, effect of inherent overstrength present in stiff structural elements to ductility distribution is clearly visualized in charts.

The ductility estimation performance of the spectra set is assessed by utilizing a 4-member shear frame system. Upon designing the system and performing inelastic dynamic analyses, computed mean ductilities are compared with chart estimations. In general, the Torsional Ductility Spectra estimates the expected ductilities of the shear frame members fairly well.

Some observations are also performed on the spectra trends. While flexible side members attain ductilities around imposed ductility reduction factors, this may not be the case for stiff side members especially when overstrength is present. Moreover, it is determined that increasing amount of torsional flexibility have a negative effect in ductility distribution of asymmetricplan systems.

The proof of concept presented herein and the simple verification with respect to shear frame behaviour are considered as the first phase of the study. As part of the ongoing research, the spectra set defined in this study is to be verified further by computing the ductility distribution of a multi-story, actual asymmetric-plan systems and assessing the estimation performance of Torsional Ductility Spectra. 


\section{REFERENCES}

[1] American Society of Civil Engineers, Minimum Design Loads for Buildings and Other Structures (ASCE/SEI 7-16), 2016.

[2] European Committee for Standardization, EN 1998-1 Eurocode 8: Design of structures for earthquake resistance, 2004.

[3] A. Rutenberg, Nonlinear response of asymmetric building structures and seismic codes: A state of the art review, in Nonlinear Seismic Analysis and Design of Reinforced Concrete Buildings, P. Fajfar, H. Krawinkler eds., Elsevier Publishers, London, 1992.

[4] A. Rutenberg, Behaviour or irregular and complex structures asymmetric structures progress since 1998. Proceedings of the 12th European Conference on Earthquake Engineering, London, United Kingdom, 2002.

[5] M. De Stefano, B. Pintucchi, A review of research on seismic behavior of irregular structures since 2002. Bulletin of Earthquake Engineering, 6, 285-308, 2008.

[6] S.A. Anagnostopoulos, M.T. Krykos, K.G. Stathopoulos, Earthquake induced torsion in buildings: critical review and state of the art. Earthquakes and Structures, 121(2), 305377,2015

[7] C.L. Kan, A.K Chopra, Torsional coupling and earthquake response of simple elastic and inelastic systems. Journal of the Structural Division, ASCE, 107, 1569-1588, 1981.

[8] A.M. Chandler, G.L. Hutchinson, Torsional coupling effects in the earthquake response of asymmetric buildings. Engineering Structures, 8, 222-236, 1986.

[9] A. Rutenberg, M. Eisenberger, G. Shohet, Reducing seismic ductility demand in asymmetric shear buildings. Proceedings of the $8^{\text {th }}$ European Conference on Earthquake Engineering, Lisbon, Portugal, 1986.

[10] A. Rutenberg, M. Eisenberger, G. Shohet, Inelastic seismic response of code designed single storey asymmetric structures. Engineering Structures, 14(2), 91-102, 1992.

[11] R. Goel, A.K. Chopra, Effects of plan asymmetry in inelastic seismic response of onestory systems. ASCE Journal of Structural Engineering, 117, 1492-1513, 1991.

[12] R. Goel, A.K. Chopra, Dual-level approach for seismic design of asymmetric-plan buildings. Journal of the Structural Division, ASCE, 120(1), 161-179, 1994.

[13] A.M. Chandler, X.N. Duan, Performance of asymmetric code-designed buildings for serviceability and ultimate limit states. Earthquake Engineering and Structural Dynamics, 26, 717-735, 1997

[14] T. Paulay, A behaviour based design approach to earthquake induces torsion, in Seismic Methodologies for the Next Generation of Codes, P. Fajfar and H. Krawinkler eds., Balkema, Rotterdam, 1997.

[15] B. Myslimaj, W.K. Tso, A design oriented approach to strength distribution in singlestory asymmetric systems with elements having strength-dependent stiffness. Earthquake Spectra, 21(1), 197-212, 2005.

[16] T. Paulay, Torsional mechanisms in ductile building systems. Earthquake Engineering and Structural Dynamics, 27, 1101-1121, 1998. 
[17] J.L. Humar, P. Kumar, Effect of orthogonal in plane structural elements on inelastic torsional response. Earthquake Engineering and Structural Dynamics, 28, 1071-1097, 1999.

[18] J.L. Humar, P. Kumar, A new look at the torsion design provisions in seismic building codes. Proceedings of the $12^{\text {th }}$ World Conference on Earthquake Engineering, Auckland, New Zealand, 2000.

[19] K.G. Stathopoulos, S.A. Anagnostopoulos, Accidental design eccentricity: Is it important for the inelastic response of buildings to strong earthquakes? Soil Dynamics and Earthquake Engineering, 30(9), 782-797, 2010.

[20] M. De Stefano, E.M. Marino, P.P. Rossi, Effect of Overstrength on the Seismic Behaviour of Multi-Storey Regularly Asymmetric Buildings. Bulletin of Earthquake Engineering, 4(1), 23-42, 2006.

[21] K. Kaatsiz, H. Sucuoğlu, The role of overstrength on the seismic performance of asymmetric-plan structures. Earthquake Engineering and Structural Dynamics, 48, 412-431, 2019.

[22] J. Hancock, J. Watson-Lamprey, N.A. Abrahamson, J.J. Bommer, A. Markatis, E. McCoy, R. Mendis, Improved method of matching response spectra of recorded earthquake ground motion using wavelets. Journal of Earthquake Engineering, 10, 67-89, 2006.

[23] PEER Ground Motion Database available from: http://ngawest2.berkeley.edu, 2020.

[24] Open System for Earthquake Engineering Simulation, available from: http://opensees.berkeley.edu, 2020. 